\title{
Pênfigo foliáceo em um eqüino
}

\author{
Pemphigus foliaceus in a horse
}

\section{Gabriel Augusto Monteiro ${ }^{\mathrm{I}}$ Maria Verônica de Souza ${ }^{\mathrm{II}}$ Lissandro Gonçalves Conceição ${ }^{\mathrm{II}}$ Camila de Lacerda Balbi e Rocha Borba ${ }^{\mathrm{III}}$ Maria Aparecida Scatamburlo Moreira ${ }^{\mathrm{IV}}$}

\section{RESUMO}

Pênfigo foliáceo é uma rara afecção cutânea autoimune que acomete várias espécies. Relata-se o caso de uma égua de quatro anos de idade, sem raça definida, apresentando áreas de alopecia, exsudação e crostas localizadas na face, região peitoral e membros pélvicos, além de prurido. Os exames laboratoriais para pesquisa de ácaros, bactérias e estruturas fúngicas foram negativos. O exame histopatológico revelou uma dermatite pustular intra-epidérmica com acantólise subcorneal, assim como dermatite perivascular superficial, com infiltração de eosinófilos, sendo o quadro compatível com pênfigo foliáceo.
\end{abstract}

- NOTA-
Palavras-chave: cavalo, alopecia, crostas, acantólise.

\section{ABSTRACT}

Pemphigus foliaceus is an uncommon autoimmune skin disorder affecting various species. A case of a 4-year-old mare of undefined breed, displaying alopecic areas, exsudation and crusty lesions on the face, breast region, and hindlimbs as well as pruritus, is reported. Laboratory exams for mite, bacteria and fungal structures were negative. Histopathological exam revealed an intra-epidermal pustule dermatitis with acantholysis, as well as superficial perisvascular dermatitis with infiltration of eosinophyles, conditions compatible with pemphigus foliaceus.

Key words: horse, alopecia, crusts, acantholysis.

O Pênfigo foliáceo (PF) é uma afecção cutânea pouco comum (POWER et al., 1982;
STANNARD, 2000), porém é a mais freqüente enfermidade auto-imune na espécie eqüina (STANNARD, 2000). Clinicamente, o PF caracteriza-se por lesões alopécicas, pustulosas e crostosas. Entretanto, os quadros com lesões alopécicas multifocais ou generalizadas constituem um desafio para o diagnóstico clínico, pois podem estar relacionados a diferentes enfermidades. O objetivo desta nota é descrever a ocorrência de pênfigo foliáceo em eqüinos em nosso país, alertando assim a comunidade acadêmica.

Não existe predileção por sexo ou idade (SCOTT et al., 1980; MORIELLO et al., 2000; STANNARD, 2000) do PF em eqüinos, mas animais da raça Appaloosa parecem ser mais freqüentemente acometidos (FADOK, 1995; OGILVIE, 2000; WHITE, 2003). Há relatos dessa afecção em animais de dois meses a 20 anos de idade. Entretanto, potros com idade igual ou inferior a um ano apresentam quadro mais discreto, podendo inclusive ocorrer regressão espontânea da doença (STANNARD, 2000; WHITE, 2003). Não há distribuição geográfica ou sazonalidade associada à ocorrência da doença (STANNARD, 2000).

No exame dermatológico, as lesões mais freqüentemente encontradas são os colaretes epidérmicos (POWER et al., 1982; LAING et al., 1992), que progride para lesões papulopustulosas, as quais

\footnotetext{
'Departamento de Veterinária, Universidade Federal de Viçosa (UFV), Viçosa, MG, Brasil.

"ISetor de Clínica, Departamento de Veterinária, UFV, s/n, 36570-000, Viçosa, MG, Brasil. E-mail:msouza@ufv.br. Autor para correspondência.

II'Curso de Veterinária, UFV, Viçosa, MG, Brasil.

${ }^{\text {IV }}$ Setor de epidemiologia, Departamento de Veterinária, UFV, Viçosa, MG, Brasil.
} 
evoluem, por sua vez, para lesões escamocrostosas e alopécicas (MORIELLO et al., 2000; VANDENABEELE et al., 2004), podendo ser acompanhadas de exudação e seborréia (STANNARD, 2000). As lesões mais crônicas mostram crostas mais espessas, com eventual pregueamento da pele (MESSER \& KNIGHT, 1982; KNOTTENBELT \& PASCOE, 1998).

As lesões geralmente têm início na face e nos membros e podem levar semanas ou meses para se tornarem generalizadas (FADOK, 1995; KNOTTENBELT \& PASCOE, 1998; WHITE, 2003; THE HORSE REPORT, 2006). Em alguns casos, podem se localizar apenas na face ou na região coronária do casco (SCOTT, 1988; STANNARD, 2000; THE HORSE REPORT, 2006). Ocasionalmente a pele do úbere e do prepúcio pode também estar acometida (WHITE, 2003). Prurido e dor podem ser observados em alguns casos (SCOTT et al., 1980; MORIELLO et al., 2000). Adicionalmente, sinais sistêmicos incluindo depressão, hiporexia, perda de peso e febre podem estar associados às lesões dermatológicas (FADOK, 1995; STANNARD, 2000).

O diagnóstico definitivo é realizado mediante exame histopatológico de biópsias cutâneas (SMITH, 1993; FADOK, 1995; STANNARD, 2000; WHITE, 2003; THE HORSE REPORT, 2006), que revelará dermatite pustular intra-epidérmica com acantólise intragranular ou subcorneal (ROTHWELL et al., 1985; LAING etal., 1992; WOLF \& RUCCO, 1997; MORIELLO et al., 2000). Neutrófilos não degenerados e número variável de eosinófilos são observados tanto na pústula como no infiltrado da derme superficial (SCOTT et al., 1980; WHITE, 2003). O diagnóstico clínico diferencial deve considerar a dermatofitose, a dermatofilose (LAING et al., 1992; STANNARD, 2000), a foliculite bacteriana (SCOTT, 1988), a sarcóide eqüino e o lúpus eritematoso (KNOTTENBELT \& PASCOE, 1998).

O tratamento consiste do uso de drogas imunossupresssoras ou agentes imunomoduladores. Os eqüinos com menos de um ano de idade tendem a apresentar melhor resposta terapêutica e não necessitam de terapia prolongada. Já nos animais adultos, tanto o tratamento como o prognóstico são menos favoráveis. Os medicamentos mais comumente utilizados são os glicocorticóides e a aurotioglicose (FADOK, 1995; MORIELLO et al., 2000; WHITE, 2003). O tratamento tópico pode ser realizado, concomitantemente, com o uso de xampu ou sabonete a base de enxofre ou de ácido salicílico.

Uma égua mestiça, sem raça definida, de quatro anos de idade foi atendida no município de Canaã/MG, com histórico de prurido, alopecia, exsudação e crostas no corpo, com oito meses de evolução. Havia sido medicada pelo proprietário com o uso de hipoclorito de sódio (água sanitária - 1:10 em água), durante um período de 10 dias consecutivos. Também foi pulverizada com repelentes para insetos nas áreas mais exsudativas.

Segundo o proprietário, houve uma discreta melhora dos sinais clínicos após o tratamento, mas com retorno ao quadro inicial, particularmente do prurido, tão logo cessada a medicação.

O exame físico-dermatológico revelou a presença de áreas multifocais de alopecia (Figura 1a), com presença de crostas melicéricas, particularmente na face, na região peitoral e membros pélvicos. Não foi constatada exsudação a partir das lesões no momento do exame. O prurido, de intensidade moderada, estava presente.

Após avaliação física do paciente, foi realizada a colheita de material para os seguintes exames complementares: pesquisa de ectoparasitas (raspado cutâneo), micológico direto (tricografia), exame citológico do esfregaço corado, culturas fúngica e bacteriana e biópsias de pele.

Para realização da cultura fúngica, os locais selecionados foram previamente higienizados com álcool a 70\%, para diminuir a população de fungos contaminantes (NOLI, 2000). O material obtido por raspado cutâneo superficial foi semeado em meio Sabouraud enriquecido e em meio seletivo para dermatófitos. Após crescimento fúngico, o material foi coletado com fita adesiva a partir de vários pontos da superfície da colônia e, em seguida, realizada coloração com azul lactofenol de algodão, para observação das estruturas fúngicas (MORIELLO, 1995).

Para a cultura bacteriana, seguiu-se a técnica descrita por SHANLEY (1990), com modificação, já que após biópsia de pele realizada com Punch, foi descartada a epiderme, com a finalidade de se reduzir o número de contaminantes. Os fragmentos foram macerados e semeados em Ágar Sangue de carneiro. Posteriormente, foram realizadas a coloração de Gram e provas bioquímicas, segundo técnica descrita por KONEMAN et al. (1997).

Nas amostras de pêlos, crostas, raspado cutâneo e biópsia de pele, não foram evidenciados ectoparasitas, estruturas fúngicas ou bactérias.

Os cortes histopatológicos de pele corados pelo H\&E revelaram discreta hiperplasia epidérmica com pequenos focos espongióticos e epiderme encimada por discreta camada ortoceratótica com focos de paraceratose. Em alguns trechos, observaram-se pústula subcórnea e crostas paraceratóticas, ambas contendo vários ceratinócitos acantolíticos (Figuras $1 \mathrm{~b}$, c) acompanhados por pequeno número de neutrófilos. Aderme superficial exibia discreto infiltrado 


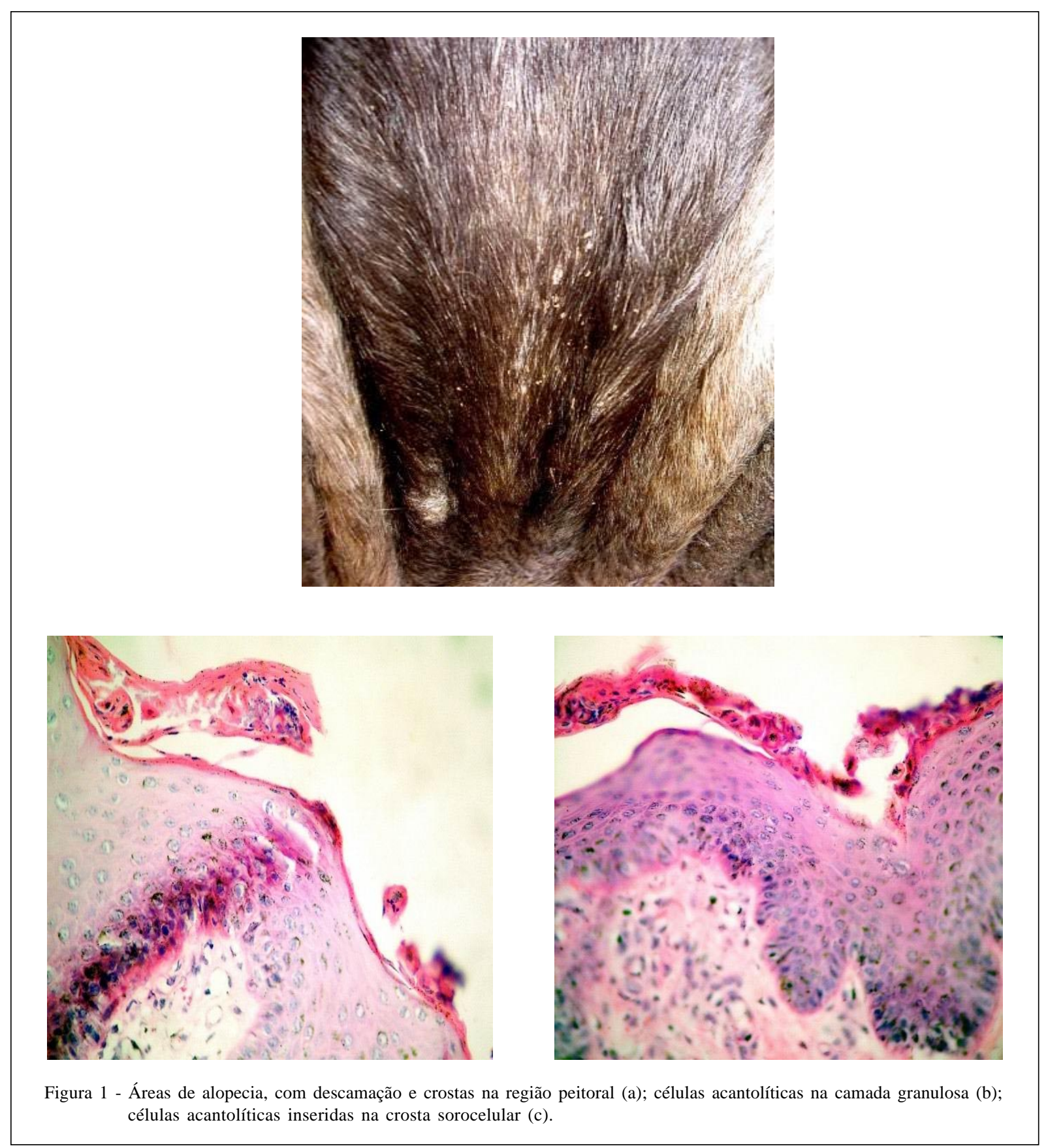

inflamatório predominantemente mononuclear com menor número de eosinófilos, possuindo arranjo angiocêntrico. Adicionalmente, na derme superficial, notaram-se alguns trechos edematosos associados a ectasia e congestão vascular. Também na histopatologia não foram observados fragmentos de ácaros nem estruturas fúngicas, inclusive em PAS. Os anexos apopilosebáceos não exibiam alterações dignas de nota.
As culturas fúngica e bacteriana foram negativas.

Os quadros clínico e histopatológico apresentados pelo animal acima mencionado são compatíveis com PF. Entretanto, os sinais apresentados podem também ocorrer em várias afecções, já amplamente descritas pela literatura científica (POWER et al, 1982; SCOTT, 1988; LAING et al., 1992; MORIELLO et al., 2000; STANNARD, 2000; SCOTT \& 
MILLER, 2003; WHITE, 2003; VANDENABEELE et al., 2004) e mencionadas anteriormente. Portanto, sem uma avaliação histopatológica, é praticamente impossível se realizar um diagnóstico definitivo de pênfigo foliáceo, tal como previamente relatado por outros autores (POWER et al., 1982; SMITH, 1993; FADOK, 1995; STANNARD, 2000; WHITE, 2003). Acantólise também pode ser um achado decorrente de infecção fúngica (SCOTT, 1994); entretanto, o raspado cutâneo, micológico direto (tricografia) e a cultura fúngica não demonstraram a presença de dermatofitose.

Apesar de o quadro acima descrito apresentar uma evolução de oito meses, este período de tempo e a intensidade da doença não foram suficientes para ocasionar o pregueamento de pele referido por MESSER \& KNIGHT (1982), o que se deve provavelmente ao curso evolutivo intermitente da doença, tal e como mencionado por SCOTT (2003), inclusive em outras espécies.

O tratamento realizado pelo proprietário não foi satisfatório, pois, como mencionado, trata-se de uma doença auto-imune (STANNARD, 2000) e, portanto, deve ser tratada com drogas imunossupressoras ou agentes imunomoduladores (FADOK, 1995; MORIELLO et al., 2000; WHITE, 2003). Também é importante o reconhecimento e a eliminação de qualquer fator que possa desencadear a doença, como a terapia prolongada com drogas, alergenos, microorganismos, insetos ou estresse (THE HORSE REPORT, 2006). O tratamento tópico, apesar de auxiliar na remoção das escamas e crostas e reduzir a possibilidade de infecção secundária (WILLIAMS, 1997), quando realizado isoladamente, não possui efeito terapêutico. Por outro lado, é possível que o tratamento tópico ou a natureza cíclica da doença tenham sido as causas da ausência, durante exame físico, da exsudação descrita por STANNARD (2000); WHITE (2003).

Nesse sentido, foi recomendado, além do tratamento local, com a retirada das crostas e escamas, terapia à base de prednisolona $\left(3 \mathrm{mg} \mathrm{kg}{ }^{-1}\right.$, dia, por via oral), inicialmente por um período de 14 dias, com posterior reavaliação para verificar a possibilidade de redução dessa dose. Entretanto, devido ao custo, o proprietário optou pela venda do animal, não permitindo o acompanhamento do caso clínico.

Com base na histopatologia, foi confirmado o diagnóstico de pênfigo foliáceo em uma égua criada no Brasil. A ocorrência deste caso serve de alerta para a existência da doença em território nacional e também confirmam a importância do exame histopatológico nas lesões alopécicas e crostosas da espécie eqüina. Nesse sentido, esta técnica deve estar entre os exames de rotina utilizados em eqüinos com problemas dermatológicos.

\section{AGRADECIMENTOS}

Os autores agradecem ao Conselho Nacional de Desenvolvimento Científico e Tecnológico (CNPq), pela concessão da bolsa de Iniciação Científica (PIBIC/CNPq) ao pesquisador Monteiro e à Fundação de Amparo à Pesquisa do Estado de Minas Gerais (FAPEMIG), pelo auxílio na publicação desse artigo.

\section{REFERÊNCIAS}

FADOK, V.A. An overview of equine dermatoses characterized by scaling and crusting. Veterinary Clinics of North America: Equine Practice, Orlando, v.11, n.1, 43-51, 1995.

KNOTTENBELT, D.; PASCOE, R.R. Sistema tegumentar. In: Afecções e distúrbios do cavalo. São Paulo: Manole, 1998. Cap.8, p.271.

KONEMAN, E.W. et al. Color atlas and textbook of diagnostic microbiology. 5.ed. Philadelphia: Lippincott, 1997. 1395p

LAING, J.A. et al. Pemphigus foliaceus in a 2-month-old foal. Equine Veterinary Journal, Newmarket, v.24, n.6, p.490491, 1992.

MESSER, N.T.; KNIGHT, A.P. Pemphigus foliaceus in a horse. Journal of American Veterinary Medicine Association, Schaumburg, v.180, n.8, p.938-940, 1982.

MORIELLO, K.A. Diagnostic testing. In: MORIELLO, K.A.; MASON, I.S. (Eds). Handbook of small animal dermatology. Kidlington: Pergamon, 1995. Cap.3, p.19-44.

MORIELLO, K.A. et al. Enfermidades da pele. In: REED, S.M.; BAYLY, W.M. Medicina interna eqüina. Rio de Janeiro: Guanabara Koogan, 2000. Cap.10, p.454-455.

NOLI, C. Practical laboratory methods for the diagnosis of dermatologic diseases. In: BONAGURA, J.D. (Ed). Kirk's current veterinary therapy small animal practice XIII, Philadelphia: Saunders, 2000. Cap.7, p.526-530.

OGILVIE, T.H. Doenças dermatológicas. In: Medicina interna de grandes animais. Porto Alegre: Artmed, 2000. Cap.16, p.415-416.

POWER, H.T. et al. Use of a gold compound for the treatment of pemphigus foliaceus in foal. Journal of American Veterinary Medicine Association, Schaumburg, v.180, n.4, p.400-403, 1982.

ROTHWELL, T.L.W. et al. Possible pemphigus foliaceus in a horse. Australian Veterinary Journal, Brunswick, v.62, n.12, p.429-430, 1985

SCOTT, D.W. Immunologic diseases. In: _____. Large animal dermatology. Philadelphia: Saunders, 1988. Cap 10, p.306-311.

SCOTT, D.W. Marked acantholysis associated with Dermatophytosis due to Trichophyton equinum in two horses. Veterinary Dermatology, Davis, v.5, n.3, p.105-110, 1994. 
SCOTT, D.W.; MILLER Jr, W.H. Immune-mediated disorders. In: ___ Equine dermatology. Philadelphia: Saunders, 2003. Cap.9, p.475-547.

SCOTT, D.W. et al. The comparative pathology of non-viral bullous skin diseases in domestic animals. Veterinary Dermatology, Davis, v.17, p.257-281, 1980.

SHANLEY, K.J. Interpreting dermatologic lesions. Part II. Diagnostic techniques. Focus on Dermatology, Pennsylvania, v.11, n.3, p.12-18, 1990.

SMITH, B.P. Moléstia da pele e dermatopatias. In:

Tratado de medicina interna de grandes animais. São Paulo: Manole, 1993. V.2, cap.38, p.1249-1251.

STANNARD, A.A. Immunologic diseases. Veterinary Dermatology, Davis, v.11, p.163-178, 2000.
THE HORSE REPORT. Everything you wanted to know (and more) about skin. Equine Dermatology, Davis, v.24, n.1, p.3-12, 2006.

VANDENABEELE, S.I.J. et al. Pemphigus foliaceus in the horse: a restrospective study of 20 cases. Veterinary Dermatology, Davis, v.15, n.6, p.381, 2004.

WHITE, S.D. Skin diseases. In: ROBINSON, N.E. Current therapy in equine medicine 5. Philadelphia: Saunders, 2003. Cap.4, p.217-218.

WILLIAMS, M.A. The skin. In: ROBINSON, N.E. Current therapy in equine medicine 4. Philadelphia: Saunders, 1997. Cap.8, p.383-384.

WOLF, R.; RUOCCO, V. Gaining more insight into the pathomechanisms of thiol-induced acantholysis. Medical Hypotheses, Oxford, v.48, n.2, p.107-110, 1997. 